\title{
BESCHOUWINGEN NAAR AANLEIDING VAN: DE GESCHIEDENIS VAN HET ECONOMISCH DENKEN
}

\author{
G. Vandewalle
}

Kluwer, Deventer-Antwerpen, 1976, pp.XII + 392, prijs f 72-

door Drs. T.J. Kastelein

Er zijn niet bijzonder veel handboeken in de Nederlandse taal geschreven, die zich bezighouden met de geschiedenis van het economisch denken. Het onderwerp als zodanig ontmoet in ons taalgebied wel belangstelling, maar dan toch voorna. melijk in de betrekkelijk beperkte kring van docenten en studenten aan univer. sitaire instellingen en het hoger beroepsonderwijs. In dit onderwijs is de ruimte voor de geschiedenis van het economisch denken na 1945 aan de meeste opleidingen ingekrompen. De vraag naar literatuur op dit terrein wordt in Nederland grotendeels gedekt door voornamelijk Engelstalige werken, die vanuit diverse gezichtspunten zijn geschreven en in uiteenlopende omvang betrekkelijk goedkoop zijn te verkrijgen.

De laatste jaren is de belangstelling voor het onderwerp in het buitenland weer enigszins toegenomen (al was het ook daar aanvankelijk vanuit het defensief), hetgeen kan blijken uit het succes van het tijdschrift History of Political Economy (sedert 1969), afkomstig uit de Verenigde Staten, en de History of Economic Thought Newsletter (sedert 1968), afkomstig uit Engeland. Binnen deze context is het dan ook opmerkelijk, wanneer er een relatief zo omvangrijk nieuw Neder. landstalig werk verschijnt over de geschiedenis van het economisch denken als dat van de Belgische hoogleraar Vandewalle. Vanzelfsprekend rijzen onmiddellijk vragen naar het gezichtspunt van de auteur met betrekking tot zijn onderwerp, de plaats van zijn geschrift naast een aantal andere Nederlandstalige werken en die uit het buitenland. Een diepgravende analyse is wat dit betreft niet geheel mo. gelijk maar een eerste plaatsbepaling wel.

Aan Schumpeter') is het onderscheid te danken, dat wel wordt gemaakt tussen geschiedenis van de analyse van economische theorieën en de geschiedenis van het economisch denken. De eerste beperkt zich inderdaad tot het denkinstrumentarium, het analytisch apparaat, de tweede omvat ook de opvattingen omtrent de mogelijke of gewenste economische ordes. Met betrekking tot de eerste zou ge. sproken kunnen worden in termen van vooruitgang van de economische weten schap, met betrekking tot de tweede zou dat niet het geval zijn. Blaug') bracht een enigszins andere onderscheiding aan, welke die van Schumpeter gedeeltelijk overlapt, en wel die tussen een absolute en relatieve benadering. De absolute be nadering richt zich op de vooruitgang van de analyse en dan voornamelijk vanuit het gezichtspunt van een wetenschapsontwikkeling als een autonoom rationeel proces. De relativistische benadering gaat er van uit dat externe factoren, zoals tijdruimtelijk gebonden sociaal-economische situaties of gebeurtenissen, psycho-

1) J. A. Schumpeter. History of Economic Analysis, London (1 954).

2) Mark Blaug, Economic Theory in Retrospect, London (19682). 
logische, wereldbeschouwelijke, culturele of filosofische opvattingen hun invloed uitoefenen op de inhoud en de analyse van de economische wetenschap. Daarmee wordt dan ook nog wel eens verdedigd dat de verklaringsmogelijkheden van economische theorieën historisch en vooral ook ideologisch zijn gebonden. Blaug moest van deze laatste relativistische benadering niet veel hebben, met name om. dat hij vond dat dit soort externe invloeden en hun werking eerder werden ge. suggereerd dan werkelijk aangetoond, terwijl zij voor het analytisch apparaat niet fundamenteel waren. Voorzover ik het terrein der handboeken overzie, zijn er maar betrekkelijk weinig absolute absolutisten en absolute relativisten. Er is eerder sprake van een spectrum dat zich tussen de beide uitersten bevindt. Dat neemt niet weg dat vele economen een voorkeur hebben voor de gedachte van een au. tonome, rationele vooruitgang van hun wetenschap.

Wat deze discussie betreft laat Vandewalle geen twijfel open, hij is een prin cipiële relativist en hij schrijft niet alleen over de geschiedenis van de economi sche analyse sec, maar over die van het denken: „De idealistische visie als zou de geschiedenis van het economisch denken kunnen worden herleid tot een debat onder grote denkers zonder enig verband met reële toestanden en problemen, werd a priori verworpen" (blz. V). En hoewel hij zegt geen streng historisch materialistische visie te willen verdedigen is het duidelijk dat in zijn opvatting de sociaal economische toestand en ontwikkeling van fundamentele betekenis zijn. Dit blijkt zowel uit de gekozen periodisering, welke vanaf 1850 wordt gekenschetst met termen als hoog.kapitalisme (1850-1895), laat-kapitalisme (1895.1936) en neokapitalisme (1936-1973), als uit de bladzijden die telkens worden besteed aan een kort overzicht van de voornaamste sociaal economische veranderingen in een be paalde te bespreken periode. Veel aandacht geeft Vandewalle ook aan de poli tieke betekenis en interpretatie van de diverse leerstelsels, zoals die in liberalisme en neo-liberalisme, socialisme in al zijn varianten, en christelijke overtuigingen tot uitdrukking komen. Toch kan niet worden gezegd dat het een doctrinair boek is. De scala van onderwerpen dat aan de orde komt is uitermate breed.

Overigens is het verstandig op deze plaats te vermelden dat de onderscheidin gen analyse-denken, absolutistisch-relativistisch niet tot misverstanden moeten leiden. Ook het boek van Thoben ${ }^{3}$ ) is naar diens visie relativistisch, zoals uit het voorwoord, eerste hoofdstuk en de telkens terugkerende paragrafen tijd en plaats blijkt, maar desalniettemin wordt de behandeling van de stof gekenmerkt door een zeer analytische methode, zoals ook in de titel tot uitdrukking komt. De term relativisme verwijst vóór alles op de niet-autonome ontwikkeling van de analyse sec.

Zo wordt ook in Vandewalle de ontwikkeling van de analyse bepaald wel ge volgd, en wordt van deze ontwikkeling zo nodig gebruik gemaakt. Noch algebraische, noch grafische presentatie worden uit de weg gegaan.

Om globaal de specifieke kenmerken van het werk van Vandewalle uit te laten komen, is onderstaande vergelijkende tabel gemaakt, waarin drie Nederlandse en drie veel gebruikte Engelstalige werken zijn opgenomen. De betekenis daarvan is uiteraard maar zeer betrekkelijk.

Vergelijking met de Nederlandstalige werken levert het volgende op. Duidelijk is wel, dat Vandewalle's boek het meest omvangrijke is, gemeten naar de hoofd.

5) H. A. A. M. Thoben, Exacte economie. Leiden $\left(1976^{-}\right.$). Dit betreft een herziene diuk van het in 1956 onder dezeilide titel uilgegeven bock vall D. B. J. Schoulen.

ma $\quad b \quad b l z 238$ 
tekst. Verder heeft zijn werk het meest uitgebreide noten-apparaat dat een goede toegang geeft tot nadere literatuur en oorspronkelijke auteurs. Het boek geeft re latief veel aandacht aan de periode van de 18 e eeuw en daarvoor. Het wordt daar. in alleen door Zimmerman overtroffen. Naar absolute omvang gemeten is het aantal bladzijden echter gelijk. Relatief besteden alle genoemde Nederlandse boe. ken evenveel aandacht aan de $19 \mathrm{e}$ eeuw tot aan de Oostenrijkse School. Het ver. gelijkbare cijfer van Vandewalle is enigszins geflatteerd, doordat de periodiserin. gen niet geheel parallel loopt. De periode tot Keynes krijgt bij Vandewalle relatief wat minder aandacht, al is het absoluut genomen niet minder dan bij Zimmer man en twee maal zoveel als bij Nentjes. De periode na Keynes krijgt bij Vande walle relatief en absoluut veel aandacht, hetgeen het boek bijzonder aantrekkelijk maakt, omdat betrekkelijk recente opvattingen daardoor eveneens aan bod komen, en naast elkaar worden gezet. De aandacht voor socialistische opvattingen is relatief en absoluut zeer uitgebreid (absoluut genomen ongeveer twee maal zoveel als bij Zimmerman en vier maal zoveel als bij Behrens en Nentjes). Sociolo gische, historische en christelijk geöriënteerde stromingen krijgen eveneens veel meer aandacht dan bij één van de andere auteurs.

Ook ten opzichte van de Engelstalige werken springt de relatief grote aandacht voor economische, historische, sociologische en psychologische stromingen eruit evenals voor de christelijke, liberale, neo liberale en socialistische overtuigingen. Te denken valt wat de laatste betreft aan de huidige neo-marxistisch georiënteerde Cambridge-economen.

Deze bespreking moet niet leiden tot de indruk dat de "groten" uit het vak niet of onvoldoende aan bod komen. De Physiocraten, de Klassieken, Oostenrijkers, Lausanners, Neo-klassieken, Scandinaviërs en Keynesianen krijgen alle aandacht. Vandewalle wijst herhaalde malen op het verschil in rol van de denkers en populariseerders en vulgariseerders. Aantrekkelijk is ook dat hij vele malen tot een afzonderlijke, reflecterende en kritische bespreking van de te berde gebrachte au. teurs en stromingen overgaat.

$\mathrm{Bij}$ dit alles legt Vandewalle getuigenis af van een grote belezenheid die hem gelukkig het overzicht niet heeft doen verliezen.

Een relativistische benadering neigt ertoe, en zeker bij een opzet als deze, om veel namen te noemen. Een aantal malen gaat de informatie dan ook niet zo. veel verder dan het noemen van de naam met een enkele aanduiding van het werk. Een enkele maal ook is de aanduiding zo beknopt dat men niet veel wijzer wordt dan de wetenschap dat een bepaalde auteur een bijdrage heeft geleverd.

Men kan van mening zijn dat onze afstand tot de recente geschiedenis te gering is om er met enige distantie over te kunnen schrijven. Het lijkt deze recensent echter toch belangrijk, dat, behalve bv. de Chicago-school onder leiding van Milton Friedman, ook, om maar een voorbeeld te noemen, auteurs als Cyert en March, H. A. Simon, G. Katona, Neumann en Morgenstern, een plaats krijgen, terwijl deze bij Behrens, Zimmerman, Roll en Blaug (wel Neumann en Morgenstern) niet aan bod komen.

Het is duidelijk dat Vandewalle een bepaalde visie op de economische wetenschap heeft, die neerkomt (zie zijn laatste paragraaf) op minder determinisme, meer socio-psychologische belangstelling, en meer empirisch onderzoek. Dat doet hem kritisch staan, zowel ten opzichte van de neo-klassieke auteurs, die te gemakkelijk de degelijkheid van het kapitalistische produktie- en verdelingssysteem 
meenden te kunnen bewijzen, als ten opzichte van de meeste neo-marxisten en sommige neo-Keynesianen, die deze degelijkheid te simpel meenden te kunnen betwijfelen.

Als men het relativisme van de auteur niet deelt en evenmin zijn visie dan zal men gemakkelijker zeggen dat er te veel in staat, dat voor de analyse sec onbelangrijk is. Maar men zal echter moeilijk kunnen ontkennen dat de andere visies, vervat in economische terminologieën en interpretaties, een bepaalde rol hebben gespeeld. Bovendien is het boek bepaald niet zo geschreven dat het relativistische standpunt een adequate plaatsbepaling van auteurs en stromingen in de weg staat.

Bij alle waardering voor dit werk, zijn er uiteraard ook wel opmerkingen te ma. ken en hier en daar vragen te stellen. Bij Adam Smith en John Stuart Mill bv. wordt behalve het geven van titels niet ingegaan op ieders andere geschriften, daarbij de indruk wekkend dat deze volledig los van hun economisch werk staan. Het lijkt mij terecht als men hier op zichzelf al een vraagteken bij zet, doch vooral in het verband van de opvatting, welke kiest voor een ruime interpretatie van economisch denken en waarbij vraagstukken van orde zo centraal staan. Bovendien wordt wel, en terecht naar het mij voorkomt, bij de vervreemdingsleer van Marx stil gestaan, welke vooral in zijn Frühschriften een rol speelde, en welker kennis volgens een aantal auteurs voor een beoordeling van bv. Das Kapital van geen betekenis is.

Een ander punt van kritiek zou kunnen zijn dat van de literatuur over de klas sieken bv. (er is de laatste jaren nogal wat geschreven en opnieuw geïnterpreteerd) relatief weinig aan bod komt. Te denken valt aan het werk van bv. Blaug, Coats, Cropsey, Hollander, Lindgren, O'Brien, Bladen en anderen. Een andere opmerking betreft de invloed die auteurs en stromingen op elkaar uitoefenen. Zo wordt bv. de invloed van physiocraten, klassieken en in het bijzonder Ricardo, op Marx niet besproken. Een bespreking van het utilitarisme, behalve een summiere aanduiding, wordt niet gegeven, hetgeen in het concept van de auteur over de geschiedenis van het economisch denken naar mijn gevoelen niet geheel terecht is.

Een geheel ander punt betreft bv. waarom de schrijver, die zo lofwaardig veel ruimte besteedt aan de recente ontwikkeling, zo weinig ruimte geeft aan de theorie over de economische orde. Bij Walter Eucken houdt het eigenlijk op. De wel. vaartseconomie wordt betrekkelijk summier behandeld. Arrow wordt bv. wel als groeitheoreticus genoemd, maar niet als iemand die zich heeft beziggehouden met de welvaartseconomie. De problemen rond economische beslissingsprocedures van collectiviteiten, o.a. in de paradox van Arrow bekend geworden, en in het werk van Olson verder uitgewerkt, krijgen verder geen aandacht. In het concept van de auteur is dat, naar mijn mening weer, enigszins bevreemdend.

Een laatste punt, dat ik zou willen noemen en waarbij ik een vraagteken zou willen stellen, betreft de methodologie. Vanzelfsprekend komt de methodenstrijd aan de orde, maar er wordt niet echt ingegaan op de problemen die nu juist in de economische wetenschap de overbrugging van theorie naar empirie zo moei. lijk maken. Vandewalle komt toch niet veel verder dan de tegenstelling inductiedeductie en daarmee wordt de problematiek versimpeld. Vanaf Adam Smith, Nassau Senior, John Stuart Mill, C. Menger, J. Schmoller, L. Robbins, W. Eucken, tot M. Friedman, T. Koopman, T. W. Hutchison, J. J. Klant, A. Lowe en vele an- 
deren is er meer aan de orde geweest. En ook hier kan men een vraag stellen, juist omdat het betoog van de schrijver uitloopt op een pleidooi voor meer empirisme, meer psychologie en minder lichtzinnig gebouwde ingewikkelde model. len. Deze problematiek had zeker ook in historisch perspectief meer aandacht kunnen krijgen.

Het is niet zo moeilijk om meer vragen te stellen en opmerkingen te maken, maar het lijkt mij niet dat dit het positieve oordeel werkelijk zou kunnen aantas. ten. De auteur heeft zijn keuze gemaakt en binnen dat kader een fraai overzicht geschreven. Tenslotte, het lijkt mij dat dit boek niet alleen aantrekkelijk is voor studerenden en speciale belangstellenden maar ook voor hen, die de studie wat langer achter de rug hebben, en die in een wat langer tijdsperspectief nog eens een overzicht willen hebben van wat er op het terrein van de algemene economie aan de hand is. De bedrijfseconomie krijgt bij Vandewalle evenmin als in één van de vergelijkbare boeken enige aandacht.

Samengevat, het lijkt mij dat het boek van Vandewalle op dit moment het uitvoerigste en meest complete overzicht in de Nederlandse taal geeft. Naar niveau is het zeker niet minder dan wat in het buitenland verschijnt. Het heeft een in vele opzichten duidelijk eigen karakteristiek, ook ten opzichte van vele buitenland. se werken, die niet in dit overzicht werden opgenomen, waardoor het een eigen plaats heeft. De prijs van tweeënzeventig gulden kan een brede verspreiding ech. ter wel eens in de weg staan.

Vergelijking van een aantal handboeken m.b.t. geschiedenis van het economisch denken $\left.{ }^{4}\right)$

\begin{tabular}{|c|c|c|c|c|c|c|c|}
\hline & Nentjes') & Behrens $\left.{ }^{6}\right)$ & Zimmerman') & Vandewalle & Blaug & Roll $\left.{ }^{9}\right)$ & Spiegel $\left.^{10}\right)$ \\
\hline omvang & XVIII +269 & 512 & 313 & XIV +392 & $\mathrm{XXIV}+710$ & 626 & $\mathrm{XIV}+81 \epsilon$ \\
\hline register & geen & $\begin{array}{l}3 \text { pers. } \\
10 \text { zaken }\end{array}$ & 8 pers. & 9 pers. & $\begin{array}{l}10 \text { pers. } \\
16 \text { zaken }\end{array}$ & $\begin{array}{l}10 \text { pers. } \\
\text { en zaken }\end{array}$ & $\begin{array}{l}22 \text { pers. } \\
\text { en zaken }\end{array}$ \\
\hline $\begin{array}{l}\text { noten en } \\
\text { aanteken. blz. }\end{array}$ & 5 & 11 & 9 & 62 & $\begin{array}{l}57 \\
+ \text { comm }\end{array}$ & 5 & $\begin{array}{l}160 \\
+ \text { comm }\end{array}$ \\
\hline woorden p. blz. & \pm 350 & \pm 360 & \pm 400 & \pm 650 & \pm 540 & \pm 360 & \pm 580 \\
\hline tekst blz. & 264 & 483 & 284 & 313 & 627 & 600 & 634 \\
\hline $\begin{array}{l}\text { tekst blz. } \mathrm{x} \text { woorden, } \\
\text { Nentjes }=100\end{array}$ & 100 & 190 & 123 & 210 & 370 & 230 & 392 \\
\hline
\end{tabular}




\begin{tabular}{|c|c|c|c|c|c|c|c|}
\hline & Nentyes $5^{5}$ & Behrens ${ }^{6}$ ) & Zimmerman & Vandewalle & Blaug & Roll $\left.{ }^{4}\right)$ & Spiegel ${ }^{10}$ ) \\
\hline $\begin{array}{l}\text { erdeling over } \\
\text { serioden in \% }\end{array}$ & 100 & 100 & 100 & 100 & 100 & 100 & 100 \\
\hline jòòr $18 \mathrm{e}$ eeuw & $1 \%$ & $3 \%$ & $10 \%$ & $6 \%$ & $4 \%$ & $18 \%$ & $23 \%$ \\
\hline $18 \mathrm{e}$ eeuw & $4 \%$ & $9 \%$ & $11 \%$ & $7 \%$ & $6 \%$ & $8 \%$ & $12 \%$ \\
\hline $\begin{array}{l}19 \text { e eeuw tot } \pm \\
1870\end{array}$ & $20 \%$ & $23 \%$ & $23 \%$ & $26 \%$ & $32 \%$ & $34 \%$ & $34 \%$ \\
\hline 1870.1936 & $57 \%$ & $58 \%$ & $41 \%$ & $25 \%$ & $53 \%$ & $18 \%$ & $17 \%$ \\
\hline ranaf 1936 & $18 \%$ & $7 \%$ & $15 \%$ & $36 \%$ & $5 \%$ & $22 \%$ & $14 \%$ \\
\hline $\begin{array}{l}\text {;ocialisme in } \\
6 \text { van tekst }\end{array}$ & $6 \%$ & $5 \%$ & $10 \%$ & $18 \%$ & $10 \%$ & $9 \%$ & $10 \%$ \\
\hline $\begin{array}{l}\text {;ocio ec. } \\
\text { cist. ec. } \\
+ \text { andere stroming in } \\
\text { \% van tekst }\end{array}$ & $5 \%$ & $4 \%$ & $5 \%$ & $12 \%$ & $0,5 \%$ & $9 \%$ & $8 \%$ \\
\hline $\begin{array}{l}\text {-elativist/ } \\
\text { absolutist }\end{array}$ & absol. & absol. & relat. & relat. & absol. & relat. & relat. \\
\hline $\begin{array}{l}\text { lgebraische en } \\
\text { zrafische presentatie }\end{array}$ & $\mathrm{ja}$ & weinig & weinig & ja & ja & niet & $\begin{array}{l}\text { vrijwel } \\
\text { niet }\end{array}$ \\
\hline
\end{tabular}

1) In dir overzicht zijn niel opgenomen het ondel noor 3 opgenomen boek van Thoben en dal van P. C. van Trab, Geschiedenis van de economie, de evolutic van een gedachtenwereld. Amsterdam (1969). De beide boeke'n zijn nogal beknoph, Thoben 155 blz.. Van Traa 198 blz. Hel boek van Thoben is geschreven vanui een rolativistisch standpunt, inala wel sterk analytisch en concentreert zich via een modelmatige alapak op enkele scholen en auteurs. Hel boek van Van Thia is eveneens vanuil een relutivistisch standpun gescheven. In kort besteh komen vrij veel auteurs en scholen anan bod.

1) A. Nentjes. De ontwikkeling van de economische theorie, Groningen (1974-).

6) H. H. Behrens, De ontwikkeling in het economisch denken, Utrechi (1969). Een van de bijzondere rrekken van dir boek is, dat het als enige uitvoeriger aandacht besreedt aan Nederlandse economen

7) L. J. Zimmerman, Geschiedenis van het economisch denke'l, Den Halag $\left(1966^{7}\right)$. Het boek van Zimmerman verscheen voor het eerst in 1947, het beleefde een aantal herdiukken, matar is sedert de jat en vijlug niet gewijzigd. Het is destijds gecritiseerd op grond van zijn relativisme. Het is ook in het buitenland vertakal.

8) Op. cil. noot 2. Het boek bevat een teer uitwoerig hoolitstuk over Marx.

9) Eric Roll. A History of Economic Though, London (1973 rev. edi.). Dit boek verscheen voor het eerst in 1938 . Het is herzien, maar is toch wet een wat ouder boek. Desondanks ondervind het nog steeds een grote belangstelling.

10) Henry W. Spiegel. The Growth of Economic Thought, relates the history of economic thought to intellectual uends from Biblical times to the present. Prentice Hall Inc. Engle wood Clills, New Jersey (1 971 ). Een zerr omvangr ijk goed loegankelijk boek. dat vooral ook door zijn zeer uitvoerige becommentarieerde literanumverwijzingen annekkelijk is. Opvillend grote andacht voor de periode vóór de 18 e eeuw. Voor de hand ligs, dat de meest alswolutistische schrijvers de minste aandach voor de periode vóor de ise eeuw hebloen. 